\title{
Evaluating the influence of information and communications technology on food security
}

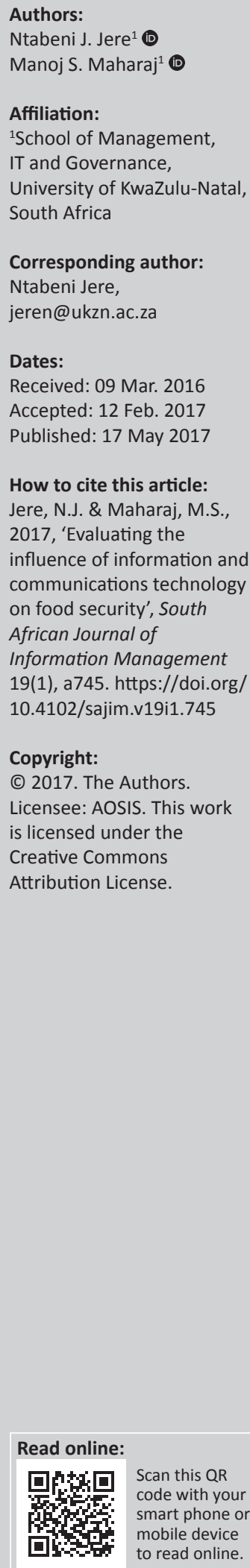

Background: This study integrates the diffusion of innovation, technology acceptance model and Hofstede's cultural dimensions theory to assess the role that information and communications technology (ICT) plays in ensuring food security. A survey of smallholder farmers from the iLembe district municipality of the KwaZulu-Natal Province of South Africa was conducted, and the data were used to test the proposed model.

Objectives: The study evaluates the influence of ICTs in improving food security in KwaZuluNatal Province. A theoretical framework was developed as the lens through which diffusion and adoption of ICTs can be understood. The theorised model was developed using constructs from the diffusion of innovation (DOI) theory, technology acceptance model (TAM) and Hofstede's cultural dimensions theory.

Method: Survey data from 517 smallholder farmers from the district municipality of iLembe were collected using a questionnaire. A quantitative approach was followed, and the developed theorised model was analysed using structural equation modelling techniques.

Results: This study proposes that ICT influence on food security is associated with culture, perceived usefulness and perceived ease of use. The study further finds that perceived ease of use of ICTs has the most significant effect with regard to ICT adoption and diffusion amongst smallholder farmers in iLembe district municipality. There are, however, no associations found with perceived attributes of innovation and the nature of social systems. The study consisted of a largely homogeneous social system; therefore, the researcher could not make any comparisons.

Conclusion: The proposed framework for evaluating the influence of ICTs on food security put forward in this study highlights a number of issues. Firstly, there is need for further study to be conducted to understand adoption of ICTs specifically for food security. This would help in creating more accurate adoption strategies. Secondly, the study informs ICT innovation developers on the need to prioritise ease of use of ICT-based interventions when developing innovations that focus on smallholder farmers. The study also contributes to policy guidelines and suggests clear guidelines be developed to address cultural aspects such as gender imbalances.

\section{Introduction}

The instability, both socially and politically, in North Africa and the Middle East in 2008 and 2011 has, in part, been attributed to poverty, unemployment and other social inequalities. These sparks of unrest also coincided with large peaks in food prices globally (Lagi, Bertrand \& Bar-Yam 2011), leading to food insecurity. The population globally is projected to exceed 9 billion by the year 2050 (United Nations 2012); this situation is very concerning, and measures to increase food security are being encouraged. Information and communications technologies (ICTs) that include mobile phones, radio, TV, computers and satellite systems have been identified as a potential contributor to achieving global food security (Bowman, Mensah \& Urama 2014).

Food security is a state that exists at household or community level when poverty has been eliminated. The inverse of this state is referred to as food insecurity, and it is closely associated with poverty and lack of access to good nutritious food (Cousins 2010; De Klerk et al. 2004; May \& Woolard 2007). Other attributes that are associated with food insecurity are unemployment and illiteracy (Duveskog, Friis-Hansen \& Taylor 2011). In South Africa, 40\% of its 50 million population live in rural areas (National Planning Commission 2012) and are largely dependent on smallholder farming to provide a means of livelihood, either through employment or through provision of food. As far back as the 1960s, the benefits and potential of smallholder farmers have been argued not only in reducing food insecurity but also in contributing to production (Schultz 1964). These farmers, therefore, need to be supported and developed (Aliber \& Hart 2009) as this would directly improve food security at a household level. One of the challenges smallholder farmers face in their 
practice is the lack of timely and accurate information. These challenges could be addressed through the implementation (and effective utilisation) of suitable ICTs (Davis, Babu \& Blom 2014).

Adejo and Haruna (2009) categorise ICTs as conventional (radio, television) and contemporary (telephones, computer or Internet). In South Africa, the Census 2011 Municipal report (StatsSA 2012) shows a decline in the number of households owning radios or landlines and an increase in the number of households owning televisions, computers and mobile phones. Mobile phone penetration has grown by 63.3\% between 2001 and 2011. This growth is mirrored by rural populations (Aker \& Mbiti 2010). This presents an opportunity for the provision of services through mobile applications in various sectors including agriculture (Somers \& Stapleton 2014). ICT application in agriculture has the potential to improve the farmers' work environment, thus increasing profitability, productivity and efficiency. This in turn impacts positively on food security.

ICTs are recognised globally as a key driver of social economic growth (Adu, Adelabu \& Adjogri 2014; Chourabi et al. 2012; Musingafi \& Zebron 2014) such that the United Nations included ICT use for information dissemination as part of the millennium development goals to be attained by 2015 for all its member states (United Nations 2010). However, this potential has not been realised in the agricultural sector in sub-Saharan Africa (Kelsey 2011; Kiplang'at 1999; Udry 2010).

There is limited research on the adoption and diffusion of ICTs by smallholder farmers in South Africa. In this article, we present a model that will guide the implementation of ICT by smallholder farmers to address the issue of food security. The article presents these findings to the research objective: To explore the adoption of ICTs by smallholder farmers and their role on influencing food security in KwaZulu-Natal.

\section{Theoretical models on information and communications technology adoption and diffusion}

This article evaluates the influence of ICTs in improving food security in KwaZulu-Natal Province. A theoretical framework was developed as the lens through which diffusion and adoption of ICTs can be understood. The theorised model was developed using constructs from the diffusion of innovation (DOI) theory, technology acceptance model (TAM) and Hofstede's cultural dimensions theory.

\section{Diffusion of innovation}

Rogers' DOI theory is widely used in information systems (IS) research with over 4000 publications on this topic (Rogers 2010). The DOI theory consists of four key components: innovation, communications channels, time and a social system.

\section{Innovation}

As defined earlier, an innovation is 'an idea, practice or project that is perceived as new by an individual or other unit of adoption' (Rogers 2003). The innovation release date is not relevant to the adopter of that innovation for as long as they perceive that innovation to be new to them, then they will still consider it an innovation.

\section{Communication channels}

Rogers (2003) defines a communication channel as 'a process in which participants create and share information with one another in order to reach a mutual understanding'. A channel is a media type through which a message is transmitted to the designated recipient.

\section{Time}

Rogers (2003) identifies the time element in the innovation diffusion process to be an important factor. The adopter classification and the rate of adoption both use the time element. The rate of adoption and the innovation-decision process all make use of the time element.

\section{Social system}

Rogers (2003) states a social system as being 'a set of interrelated units engaged in joint problem solving to accomplish a common goal'. Due to the fact that innovation diffusion takes place within a social system, the nature of that social system impacts on individual's innovativeness.

This study used Roger's DOI theory because this theoretical framework has frequently been reviewed to take into account the changing societies we live in including the various cultural differences that exist in them (Rogers 1995, 2003, 2010). This theory is the most established diffusion theory and more encompassing in terms of the variables it addresses unlike most other technology diffusion models (Bagchi \& Udo 2007; Venkatesh et al. 2003), thereby providing a more comprehensive understanding of diffusion of technology. It provides an added advantage in that it is widely used in IS research (Kapoor, Dwivedi \& Williams 2014). DOI is applicable at both micro level of social systems (individual level) and its relevance at the macro level (organisational level). Sharif, Troshani and Davidson (2014) offer the theory's simplicity as an advantage.

\section{Technology acceptance model}

The TAM is also widely employed in IS research and was selected to complement the DOI theory. TAM consists of imbedded aspects of behavioural intentions; this is due to the fact that the TAM theory originates from the theory of reasoned action which was modified in the TAM theory although now specifically towards IS.

It was included in this study to provide insight on how ICT adoption and diffusion amongst smallholder farmers in KwaZulu-Natal may be improved. TAM may also be used to explain an individual's behaviour regarding a wide range of 
technologies (Davis 1989). TAM is applied at an individual level and is based on the argument that individuals use technology for personal achievements, that is, improving your personal effectiveness, increasing work output by the individual and enhancing the decision-making process.

\section{Hofstede's cultural dimensions}

Hofstede (1980) states that 'the collective mental programming of the people in an environment' is referred to as culture. The author goes further to say 'culture refers to the collective mental programming that these people have in common, the programming that is different from other groups'. Hofstede's cultural dimensions are used extensively in studies to determine the influence of culture on values (Hofstede 1980). Hofstede's research on IBM employees from over 70 countries gave rise to his definition of culture being a conditioning of behaviours of a group to be similar with one another but can be differentiated from other groups (Hofstede 2001). Hofstede identifies five cultural dimensions that are discussed subsequently.

\section{Power distance}

This refers to the extent to which a society gives credence to the fact that there is an unequal distribution in power within an organisation, that is, the distribution of power between people in authority and their subordinates and also between various organisations (Hofstede 1980).

\section{Uncertainty avoidance}

Hofstede (1980) states that uncertainty avoidance refers to the 'extent to which a society feels threatened' by unclear and inexplicit situations.

\section{Individualism versus collectivism}

The individualism versus collectivism dimension refers to the extent to which individuals are integrated into a society or an organisation.

\section{Masculinity versus femininity}

The masculinity versus femininity dimension focuses on gender and the characteristics that are generally attributed to either masculinity or femininity.

\section{Long-term versus short-term orientation}

The long-term versus short-term orientation dimension is an extension to Hofstede's original model and was originally referred to as 'Confucian dynamism'. This dimension refers to individuals and societies focus using the time factor as the main determinant (now or future oriented) of how effort should be applied to tasks and the importance an individual applies towards tradition.

Constructs from DOI and TAM represented technological and social factors, whereas constructs from Hofstede's cultural dimensions represented cultural factors associated with adoption of ICTs amongst smallholder farmers and their relationship with agricultural extension officers.
A criticism of diffusion models such as the DOI and TAM is that they do not take into account external influences such as organisational or environmental factors (Bagchi 2001; Lee \& Cheung 2004). Studies have shown the need to understand other factors such as social-cultural and organisational factors together with technological factors (Bakkabulindi, Nkata \& Amin 2008; Damanpour \& Schneider 2009) in order to more holistically understand innovation diffusion research. This shortcoming was addressed by the inclusion of Hofstede's cultural dimensions theory that provided an added perspective of understanding the influence that culture has on the ICT innovation adoption process by smallholder farmers. Figure 1 illustrates how the constructs of the three theories were used in this study.

\section{Materials and methodology}

The study adopted a quantitative approach. The study population was identified through formal structures in the municipality, in particular in conjunction with organisations in the municipality such as Enterprise iLembe and the Economic Development Agency for the iLembe district municipality. A population of 1008 smallholder farmers was identified. Taking into consideration the design effect (Kish 1965) which refers to an approximation of the extent to which this supposition is violated with a contingency of $5 \%$, a sample of 517 smallholder farmers were surveyed.

The survey instrument was developed with insights from IT experts, experts from the School of Agriculture/Food Security Center at the University of KwaZulu-Natal and experts from the government department of agriculture head office in Cedara (strategic support services which is the unit that is involved in training of extension officers and the food security unit in the government department of agriculture). The smallholder questionnaire was translated into IsiZulu,

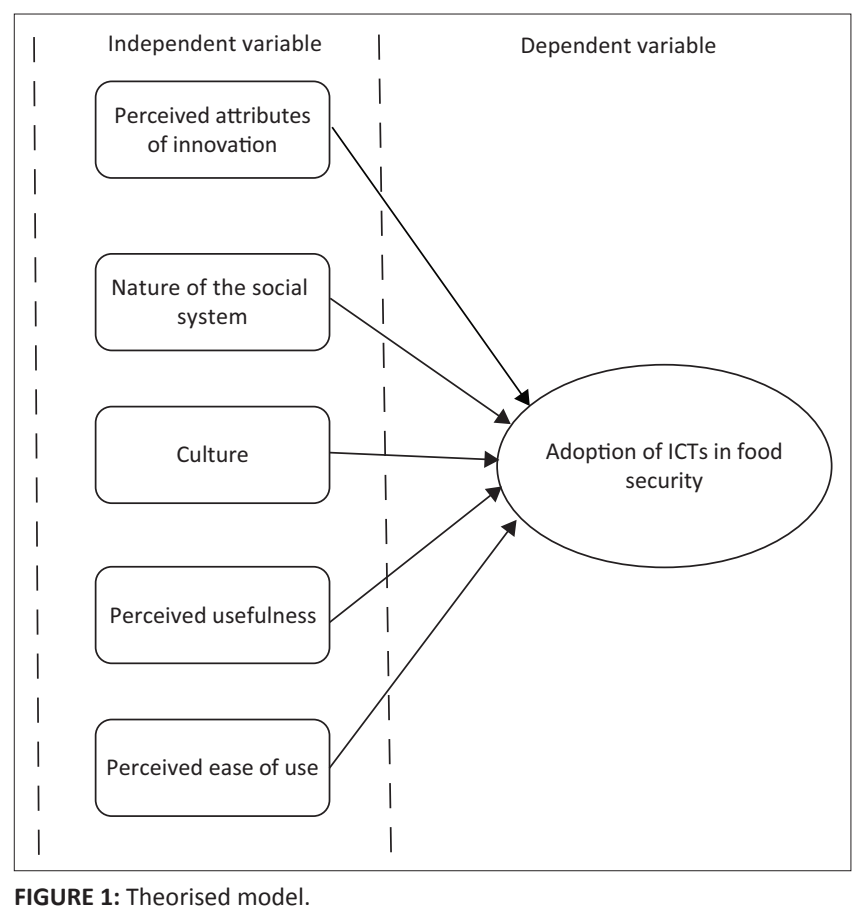


the local language of the research area. Research assistants were trained to administer the questionnaire.

Structural equation modelling (SEM) was the method of analysis employed in this study. This technique is mostly confirmatory by nature rather than being of an exploratory nature (Byrne 2013, 2016; O’Rourke \& Hatcher 2013). It is for this reason that the technique was most suitable as it assists to determine the validity of a model rather than the most suitable one. The ability to use multiple measures in association with a single latent construct also made the choice of using the SEM technique attractive in this study.

The results of the Cronbach's alpha reliability (Tavakol \& Dennick 2011) are presented in Table 1 which demonstrate good instrument reliability (above the recommended value of 0.7$)$.

\section{Findings and discussions}

Based on the quantitative data collected via a survey questionnaire, the validity of the theorised model (Figure 1) was tested using SEM and hence served more as a confirmatory analysis.

The model then required to be interpreted and the impact of each variable analysed using path analysis. The results of each path are then presented graphically and in table format. During the SEM analysis, it was of importance to analyse the 'fit' of the theorised model as this would help provide an understanding of how well it models the data. It is based on this fit that the theorised model will be accepted or rejected.

Chi-square, root mean square error of approximation (RMSEA), relative fit index (RFI) and incremental fit index (IFI) are the various goodness of fit indices that are produced as AMOS outputs (Byrne 2013). The interrelated nature and similarity of conclusion by these various indices relate to goodness of fit of the model to data provided.

The concept of goodness of fit relates to how well the data fits the model. According to Byrne (2013), an indication of good model fit is when the RFI is $\geq 0.95$ and the RMSEA value is below 0.05 with a $p$-value above 0.05 . Lei and $\mathrm{Wu}$ (2007) concur with these findings and suggest an RMSEA value of $\leq 0.06$ as an indication of good model fit. IFI is not impacted by sample size and a good fitting model based on IFI indices are values in the range of 0.95 (Byrne 2013; Newsom 2012).

An analysis using SEM revealed that the theorised model did not fit the data well because of a significant chi-square test statistic, that is, $\chi^{2}=524.695$ and $p=0.000$. Modifications were then made to the theorised model and a revised model

TABLE 1: Results of Cronbach's alpha reliability analysis: Farmer questionnaire.

\begin{tabular}{|c|c|c|}
\hline Questions & Similarity of scale & Cronbach's alpha \\
\hline $\begin{array}{l}12,14,18,29,31,35 \\
\text { and } 37\end{array}$ & $\begin{array}{l}\text { Very small extent to very } \\
\text { large extent }\end{array}$ & 0.764 \\
\hline $11,13,25-28$ & Strongly disagree to strongly agree & 0.73 \\
\hline 21 and 24 & More than once per day to never & 0.749 \\
\hline
\end{tabular}

(Figure 2) proposed in order to get a good fit to the data. The revised model and its implications to the existing theories are then discussed in relation to the initial proposed model.

The model was analysed in AMOS (version 21) and the results are given in Figure 3.

The variables of culture, perceived usefulness and perceived ease of use were all significant in their influence of the role of ICTs in food security with $p$-values all less than 0.05 (Table 2).

The initial model produced a chi-square test result of 3.423 and had a $p$-value of 0.133 . These initial results are considered to be non-significant at the $5 \%$ level and based on this the SEM indicated that the theorised model does not fit the data well. The revised model, on the contrary, using the SEM technique was considered to have been a good fit for the data (Bollen 2014; Byrne 2013). The produced results for the revised model revealed the following indices: the RFI was 0.971 , and the RMSEA was 0.008 with a $p$-value of 0.899 . In addition to this, the IFI result was 0.959 . The resulting indices all confirmed a good fit of the revised model to the data.

\section{The results reveal the following}

Perceived ease of use has the most significant influence on the role of ICT in food security. The most significant variable

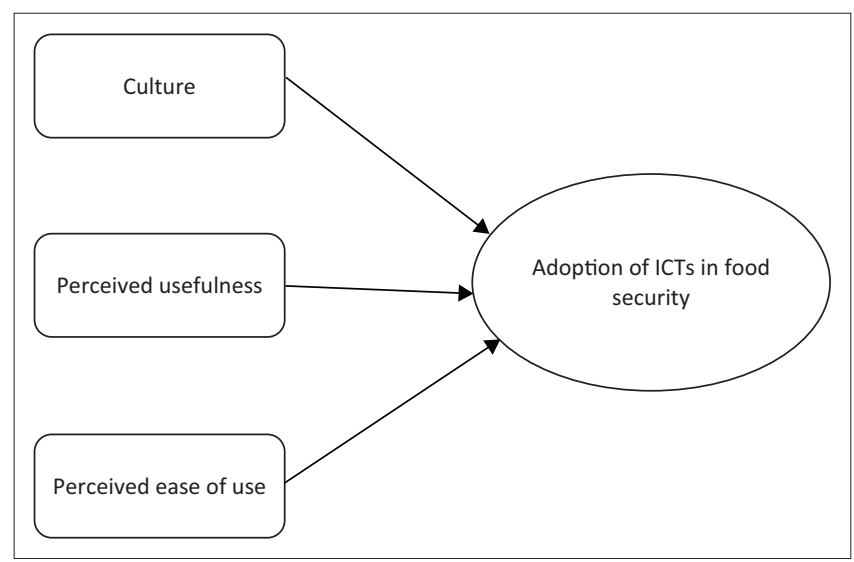

FIGURE 2: Revised model.

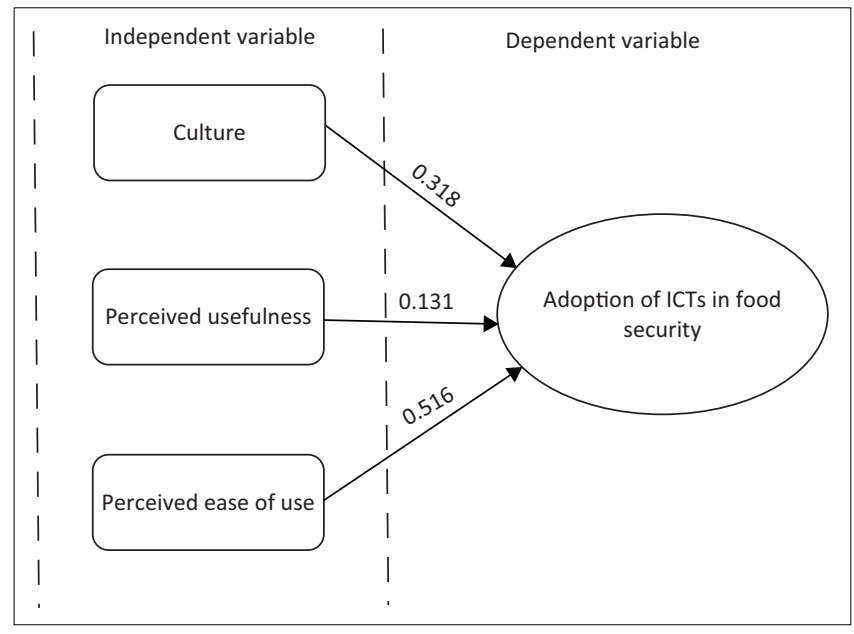

FIGURE 3: Revised model showing weights. 
TABLE 2: Regression weights.

\begin{tabular}{lllcccc}
\hline Dependent variable & Path & Independent variables & Estimate & S.E. & \multicolumn{1}{c}{ C.R. } \\
\hline Role of ICTs & $<---$ & Culture & 0.318 & 0.074 & 4.310 \\
Role of ICTs & $<---$ & Perceived usefulness & 0.131 & 0.043 & 3.060 \\
Role of ICTs & $<---$ & Perceived ease of use & 0.516 & 0.042 & 0.002 & 12.405 \\
\hline
\end{tabular}

S.E., standard error; ICTs, information and communications technologies; C.R., critical ratio.

in the revised model originates from the TAM put forward by Davis (1989). Perceived ease of use is one of two variables (the second being perceived usefulness). The results of the analysis reveal that much as both constructs from TAM are important and significantly impact ICT adoption for food security, perceived ease of use is of more importance. This result is in line with findings in studies such as that of Van Der Heijden (2004). Based on the results, the smallholder farmers might find perceived ease of use, to be the most important construct in ICT adoption for food security due to the tasks that the ICTs are used for (Gefen \& Straub 2000). Literacy levels also play a role in creating complexity and hence the easier it is to use an ICT the more useful the farmers will find that technology, this is the position held by authors such as Venkatesh (2000). It is therefore understandable that smallholder farmers might find the aspect of how easy it is to use an ICT of most importance rather than its utility. ICT developers and marketers need to always consider the ease of using the technology when attempting to deploy technology amongst smallholder farmers.

Perceived usefulness also significantly impacts the role of ICT in food security. It is evident that perceived usefulness of ICTs in food security is an important construct in understanding ICT adoption in food security by smallholder farmers. The findings of this study revealed that much as perceived usefulness might have a lesser significance to that of perceived ease of use specifically amongst smallholder farmers, it is the second most significant determinant to ICT adoption in food security amongst farmers. Van Der Heijden (2004) expounds that for utilitarian IS, which is IS that are focused on improving performance, perceived usefulness is the most important construct. The inclusion of ICTs in food security is an attempt at using all available technologies and methods to create food secure communities. It is therefore important to recognise the importance of the perceived usefulness of an ICT innovation. When developing ICT innovations for farmers in food security, these systems should include a strong focus on improving farmer performance, as this is their primary goal in being included in the food security field. It is also important to note that no amount of ease of use of a technology will replace the level of usefulness of that technology (Keil, Beranek \& Konsynski 1995).

Culture is one of the important predictors of ICT adoption and diffusion amongst smallholder farmers, and this has a significant positive effect on ICT influence on food security. The results reveal that for technology adoption amongst smallholder farmers to be successful, the construct of culture has to be taken into consideration (Hofstede 1980). As the technology diffusion is amongst people, aspects such as the interactions between smallholder farmers and other stakeholders such as extension officers need to be taken into consideration. The extent to which these various stakeholders assist the smallholder farmers in decision-making for farming processes is also important. It is through understanding these cultural norms and interactions that successful ICT innovation implementation can take place.

The nature of the social system and perceived attributes of innovation have no significant direct impact on ICT influence in food security.

\section{Proposed future work}

The proposed theoretical model that was developed based on the literature review that was conducted and later revised based on the findings lends itself to testing in different similar environments (rural communities) and is open to further advancements. Further analysis on the relationships between the measured variables could improve the model and provide insights to the relationships that exist. A suggestion would be to test specific ICTs individually as this may provide a better focus in the survey instrument and the results that follow. Further research is also proposed in shedding more light on the above findings.

\section{Conclusion}

With food security having gained global attention and its inclusion as one of the sustainable development goals (SDGs), the idea of harnessing the potential benefits of ICTs in food security is gaining ground. It is thought that farmers in their farming practices can utilise the benefits that ICTs bring to improve their production and distribution processes. Based on the potential benefits of ICTs in food security, it is important to understand ICT adoption and its influence on food security. The broad nature of ICTs is somewhat problematic when it comes to identifying adoption and diffusion variables. Van Der Heijden (2004) addresses this issue by classifying IS as being utilitarian or hedonic in nature to help better understand user adoption of technology. It is found that in hedonic systems, the perceived ease of use is the predominant variable in determining the adoption of a technology unlike in utilitarian systems where perceived usefulness is the predominant variable. Various literatures have identified perceived ease of use and perceived usefulness as being critical variables in understanding user technology adoption.

This study proposes a framework for evaluating the influence of ICTs on food security. The resulting findings in this study support existing literature identifying perceived usefulness and perceived ease of use as key variables in understanding user adoption of technology. General technology adoption 
literature identifies perceived usefulness as the primary variable used in the understanding of technology adoption and perceived ease of use as the secondary support variable. Despite this general trend, this study finds that perceived ease of use of ICTs has the most important effect with regard to ICT adoption and diffusion amongst smallholder farmers in iLembe district municipality having a weighting of over $50 \%$. In this study, perceived usefulness is the second most important variable in understanding technology adoption amongst smallholder farmers. The study also finds that technology adoption does not just involve the perceptions of the technology but that attention should also be placed on the cultural aspects that exist in that social system and the interactions between the various key role players such as extension officers. The study also showed that perceived attributes of innovation and nature of the social system does not have a significant impact on its influence on ICT adoption and diffusion amongst farmers.

The results of this study call for a number of recommendations. Further study should be done to better understand adoption of specific ICTs for food security. This will avoid generalisation and a more accurate adoption strategy to be created for smallholder farmers. ICT innovation developers should consider the findings of this study and prioritise the ease of use of ICT-based interventions when dealing with smallholder farmers. Clear policy guidelines should also be set out that address cultural aspects such as gender imbalances, reducing bureaucracy to create clear channels of communication between smallholder farmers and other stakeholders.

\section{Acknowledgements Competing interests}

The authors declare that they have no financial or personal relationship(s) that may have inappropriately influenced them in writing this article.

\section{Authors' contributions}

N.J.J. was the project leader and M.S.M. was responsible for conceptual contributions and proofing.

\section{References}

Adejo, P. \& Haruna, U., 2009, 'Access of farmers to ICTs for agricultural development in Bauchi local government area, Bauchi state', in Proceedings of the 43rd Annual Conference of the Agricultural Society of Nigeria, Abuja, October 20-23, 2009, pp. 704-707.

Adu, E.O., Adelabu, O. \& Adjogri, S.J., 2014, 'Information and Communication Technology (ICT): The implications for sustainable development in Nigeria', in World Conference on Educational Multimedia, Hypermedia and Telecommunications, Tampere, Finland, June 23, 2014, pp. 50-58.

Aker, J.C. \& Mbiti, I.M., 2010, 'Mobile phones and economic development in Africa', The Journal of Economic Perspectives 24, 207-232. https://doi.org/10.1257/ jep.24.3.207

Aliber, M. \& Hart, T.G., 2009, 'Should subsistence agriculture be supported as a strategy to address rural food insecurity?', Agrekon 48, 434-458. https://doi.org/ 10.1080/03031853.2009.9523835

Bagchi, K., 2001. 'The impact of national culture and other national-level indicators on information technology (IT) diffusion', PhD dissertation, Florida Atlantic University.

Bagchi, K. \& Udo, G., 2007, 'Empirically testing factors that drive ICT adoption in Africa and OECD set of nations', Issues in Information Systems 8, 45-52.

Bakkabulindi, F., Nkata, J. \& Amin, M.E., 2008, 'Organizational characteristics as correlates of ICT adoption in Makerere University', Kampala International University Research Digest 1, 124-137.
Bollen, K.A., 2014, Structural equations with latent variables, Wiley, Hoboken, NJ.

Bowman, W., Mensah, M. \& Urama, K., 2014, 'Information and telecommunication technologies in Africa: A potential Revolution?', Innovation for Sustainable Development 6, 45-50.

Byrne, B.M., 2013, Structural equation modeling with AMOS: Basic concepts, applications, and programming, Routledge, Abingdon.

Byrne, B.M., 2016, Structural equation modeling with AMOS: Basic concepts, applications, and programming, Routledge, Abingdon.

Chourabi, H., Nam, T., Walker, S., Gil-Garcia, J.R., Mellouli, S., Nahon, K., 2012 'Understanding smart cities: An integrative framework', in 2012 45th Hawail International Conference on System Science (HICSS), Maui, HI, January 4-7, IEEE, pp. 2289-2297.

Cousins, B., 2010, What is a 'smallholder'? PLAAS, University of the Western Cape, Cape Town, Working Paper, 16.

Damanpour, F. \& Schneider, M., 2009, 'Characteristics of innovation and innovation adoption in public organizations: Assessing the role of managers', Journal of Public Administration Research and Theory 19, 495-522.

Davis, K., 1989, 'Perceived usefulness, perceived ease of use and acceptance of information technology', MIS Quarterly 13, 319-340.

Davis, K., Babu, S.C. \& Blom, S., 2014, The role of extension and advisory services in building resilience of smallholder farmers, International Food Policy Research Institute, Washington, DC.

De Klerk, M., Drimie, S., Aliber, M., Mini, S, Mokoena, R., Randela, R, 2004, Food security in South Africa: Key policy issues for the medium term, Human Sciences Research Council Integrated Rural and Regional Development Position Paper, Research Council Integrated Rural and Regio
Human Sciences Research Council, Pretoria.

Duveskog, D., Friis-Hansen, E. \& Taylor, E.W., 2011, 'Farmer field schools in rural Kenya: A transformative learning experience', The Journal of Development Studies 47, 1529-1544. https://doi.org/10.1080/00220388.2011.561328

Gefen, D. \& Straub, D.W., 2000, 'The relative importance of perceived ease of use in IS adoption: A study of e-commerce adoption', Journal of the Association for Information Systems 1, 8 .

Hofstede, G. (ed.), 1980, Culture's consequences, Sage, Newbury Park, CA

Hofstede, G., 2001, 'Identifying organizational subcultures: An empirical approach', Journal of Management Studies 35, 1-12.

Kapoor, K.K., Dwivedi, Y.K. \& Williams, M.D., 2014, 'Rogers' innovation adoption attributes: A systematic review and synthesis of existing research', Information Systems Management 31(1), 74-91. https://doi.org/10.1080/10580530.2014. Systems
854103

Keil, M., Beranek, P.M. \& Konsynski, B.R., 1995, 'Usefulness and ease of use: Field study evidence regarding task considerations', Decision Support Systems 13, 75-91. https://doi.org/10.1016/0167-9236(94)E0032-M

Kelsey, J., 2011, Market inefficiencies and the adoption of agricultural technologies in developing countries, White Paper, Agricultural Technology Adoption Initiative, Abdul Latif Jameel Poverty Action Lab, MIT, Cambridge, MA.

Kiplang'at, J., 1999, 'An analysis of the opportunities for information technology in improving access, transfer and the use of agricultural information in the rura areas of Kenya', Library Management 20, 115-128.

Kish, L., 1965, Survey sampling, Wiley, New York.

Lagi, M., Bertrand, K.Z. \& Bar-Yam, Y., 2011, 'The food crises and political instability in North Africa and the Middle East', arXiv preprint arXiv:1108.2455.

Lee, S. \& Cheung, C., 2004, 'Internet retailing adoption by small-to-medium sized enterprises (SMEs): A multiple-case study', Information Systems Frontiers 6, 385-397. https://doi.org/10.1023/B:ISFI.0000046379.58029.54

Lei, P.W. \& Wu, Q., 2007, 'Introduction to structural equation modeling: Issues and practical considerations', Educational Measurement: Issues and Practice 26, 33-43. https://doi.org/10.1111/j.1745-3992.2007.00099.x

May, J. \& Woolard, I., 2007, Poverty traps and structural poverty in South Africa: Reassessing the evidence from KwaZulu-Natal, Chronic Poverty Research Centre, Manchester, Working Paper 82.

Musingafi, M.C. \& Zebron, S., 2014, 'The role of information and communication technology in rural socio-economic development in Africa', International Journal of Public Policy and Administration Research 1, 38-46.

National Planning Commission, 2012, National Development Plan 2030: Our Future Make It Work, Government of South Africa, Pretoria.

Newsom, J., 2012, 'Some clarifications and recommendations on fit indices', USP 655, 123-133.

O'rourke, N. \& Hatcher, L., 2013, A step-by-step approach to using SAS for factor analysis and structural equation modeling, Sas Institute, Cary, NC.

Rogers, E.M., 1995, Diffusion of innovations, Collier Macmillan, New York.

Rogers, E.M., 2003, Diffusion of Innovations, Free Press, New York.

Rogers, E.M. (ed.), 2010, Diffusion of innovations, Simon and Schuster, New York, NY.

Schultz, T.W., 1964, Transforming traditional agriculture, Yale University Press, New Haven, CT.

Sharif, M.H.M., Troshani, I. \& Davidson, R., 2014, 'Adoption of social media services: The case of local government', in Z. Sun \& J. Yearwood (eds.), Handbook of research on Demand-Driven Web Services: Theory, technologies, and applications, pp. 287-303, IGI Global, Hershey, PA.

Somers, S. \& Stapleton, L., 2014, 'e-Agricultural innovation using a human-centred systems lens, proposed conceptual framework', Al \& Society 29, 193-202. https:// doi.org/10.1007/s00146-013-0475-x 
StatsSA, 2012, Census 2011 Municipal report KwaZulu-Natal, Statistics South Africa, Pretoria.

Tavakol, M. \& Dennick, R., 2011, 'Making sense of Cronbach's alpha', International Journal of Medical Education 2, 53. https://doi.org/10.5116/ijme.4dfb.8dfd

Udry, C., 2010, 'The economics of agriculture in Africa: Notes toward a research program', African Journal of Agricultural and Resource Economics 5, 284-299.

United Nations, 2010, We can end poverty 2015 millenium development goals, viewed 18 July 2014, from http://www.un.org/millenniumgoals/
United Nations, 2012, World Agriculture towards 2030/2050: The 2012 Revision, Food and Agriculture Organization of the United Nations, Rome, Italy.

Van Der Heijden, H., 2004, 'User acceptance of hedonic information systems', MIS Quarterly 28(4), 695-704.

Venkatesh, V., 2000, 'Determinants of perceived ease of use: Integrating control, intrinsic motivation, and emotion into the technology acceptance model', Information Systems Research 11, 342-365. https://doi.org/10.1287/isre.11.4.342.11872

Venkatesh, V., Morris, M., Davis, G. \& Davis, F., 2003, 'User acceptance of information technology: Toward a unified view', MIS Quarterly 27, 425-478. 